Sharif University of Technology
Scientia Iranica
SCIENTIA
IRAN I CA
http://scientiairanica.sharif.edu

\title{
Simultaneous analysis and optimal design of truss structures via displacement method
}

\author{
A. Kaveh* and Sh. Bijari \\ Centre of Excellence for Fundamental Studies in Structural Engineering, Iran University of Science and Technology, Narmak, \\ Tehran, P.O. Box 16846-13114, Iran.
}

Received 6 August 2018; accepted 12 January 2019

\author{
KEYWORDS \\ Displacement method; \\ Metaheuristic \\ algorithms; \\ Simultaneous analysis \\ and design; \\ Optimization; \\ Truss structures; \\ Strain energy.
}

\begin{abstract}
This study proposes an efficient technique called displacement method of analysis and applies three metaheuristic algorithms, namely Colliding Bodies Optimization (CBO), Enhanced Colliding Bodies Optimization (ECBO), and Vibrating Particles System (VPS), to perform the simultaneous analysis and optimal design of trusses. The proposed method was applied to the minimum weight design of some planar and spatial truss structures. To investigate the accuracy and effectiveness of the presented method, the problems were designed using the same metaheuristic algorithms through pure force and pure displacement methods as analysis tools (non-simultaneous). Then, the resulting structural weights were compared.
\end{abstract}

(C) 2020 Sharif University of Technology. All rights reserved.

\section{Introduction}

In engineering problems of multiphysics nature, developing methods of higher computational efficiency is an important issue. The analysis and design of structures characterized by a large number of members require large memory size and high computational time. This rather expensive computation has to be repeated in an optimal design many times (e.g., over 5,000 times) since the cross-section size of the members is not determined in the early stages of designing these structures. Thus, reducing the size of structural matrices and eliminating undue repetitions in the analysis and design of structures can ensure high computational efficiency [1]. The aforementioned objective is realized in this paper through meta-heuristics algorithms and the indirect minimization of the energy function. Further to this,

\footnotetext{
*. Corresponding author. Tel.: +982144249493;

Fax: +9821 7r240398

E-mail address: alikaveh@iust.ac.ir (A. Kaveh)
}

the design process and minimization of the weight of a structure are combined with the analysis process.

One of the recently developed, powerful metaheuristic techniques is the Vibrating Particles System (VPS). The VPS is a population-based optimization procedure which is inspired by the free vibration of single-degree-of-freedom systems with viscous damping [2]. In this algorithm, the solution candidates are considered as agents that gradually approach their equilibrium positions. To ensure a proper balance between exploration (global search) and exploitation (local search), equilibrium positions are obtained from the current population and historically best positions.

Meta-heuristic algorithms are shown to be powerful tools for optimizing problems with search spaces being complex, nonlinear, and non-convex. This is especially the case when near-global optimum solutions are sought after using a limited amount of computational effort. Some examples of meta-heuristic algorithms consist of Genetic Algorithms (GA) [3], Particle Swarm Optimization (PSO) [4], Ant Colony Optimization (ACO) [5], Harmony Search (HS) [6], Big Bang-Big Crunch (BB-BC) [7], Firefly Algorithm (FA) 
[8], Magnetic Charged System Search (MCSS) [9], Bat Algorithm (BA) [10], Teaching Learning Based Optimization (TLBO) [11], Colliding Bodies Optimization (CBO) [12], Water Cycle, Mine Blast and Improved Mine Blast algorithms (WC-MB-IMB) [13], Search Group Algorithm (SGA) [14], the Ant Lion Optimizer (ALO) [15], the whale optimization [16], and Vibrating Particles System (VPS) [17]. Metaheuristic algorithms have many applications, some of which are given in [18].

Weight structural optimization can be achieved by minimizing the complementary strain energy for analysis [1] instead of applying the direct solution of classic equations, which not only prevents repetitive computations for the design and analysis, but also does not require finding the inverse of large matrices. Therefore, one needs to formulate necessary equations based on the minimum energy principle and use them in an efficient optimization procedure. In this paper, the metaheuristic algorithms and the displacement method are combined to perform simultaneous analysis and design by CBO, ECBO, and VPS. To this end, strain energy formulation is used and the related variables constitute design variables and analysis variables (nodal degrees of freedom of the structure).

The rest of this paper is structured as follows. In Section 2, energy formulation based on the displacement method is presented and $\mathrm{CBO}, \mathrm{ECBO}$, and VPS algorithms are applied to the analysis procedure. In Section 3, weight minimization is performed by considering the analysis procedure as a constraint in $\mathrm{CBO}, \mathrm{ECBO}$, and VPS methods. In Section 4, four structural design examples are studied. Some concluding remarks are given in Section 5 .

\section{Analysis by displacement approach and metaheuristic algorithms}

The main purpose of this section is to minimize the strain energy using the metaheuristic algorithms, satisfying all the necessary compatibility conditions. The formulation is based on the minimum work principle provided by Kaveh and Rahami [1].

Let $p=\left\{p_{1}, p_{2}, \ldots, p_{\alpha N}\right\}^{t}$ and $\mathrm{v}=\left\{v_{1}, v_{2}, \ldots\right.$, $\left.v_{\alpha N}\right\}^{t}$ be the joint loads and joint displacements of a structure, respectively. The force-displacement relationship for the structure can be written as follows:

$$
\{p\}=[K]\{v\},
$$

where $K$ is the symmetric $\alpha N \times \alpha N$ matrix, known as the stiffness matrix of the structure [1],[19]. The strain energy, $U$, can be expressed as follows:

$$
U=\frac{1}{2}\{v\}^{t}[K]\{v\}-\{v\}^{t}\{p\} .
$$

Now, $\{v\}$ should be calculated such that $U$ reaches its minimum point by metaheuristic algorithms.

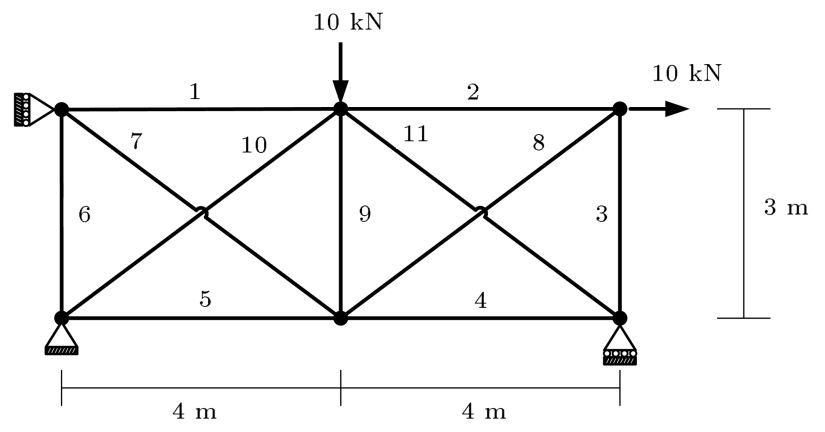

Figure 1. A simple planar truss.

In order to minimize $U, \mathrm{CBO}, \mathrm{ECBO}$, and VPS algorithms are used that are based mainly on the algorithms used in [12], [20], and [2], respectively. To demonstrate the accuracy of the analysis by the present approach, one example is presented.

A simple truss with 11 bar elements is considered, as shown in Figure 1. This structure has eight degrees of kinematic indeterminacy. Thus, $U$ should be formed in terms of eight unknowns.

The exact calculation of $U_{c}$ and $U$ is performed by the force method and displacement method respectively, the values of $U$ and $\{v\}$ obtained using the present approach are shown in Table 1. The population size of this example in all of the three algorithms is set to 20 .

\section{Optimal design using displacement approach and metaheuristic algorithms}

In this section, design and optimization processes are added to the analysis presented in the previous section. The objective function in the simultaneous analysis and design of an optimal structure is formulated by the following approach:

To minimize weight, Eq. (2) is modified such that its minimum value becomes zero. To this end, when the sum of complementary energy and strain energy is zero, the structure is in equilibrium and compatible state. Therefore, the sum of the complementary energy and the strain energy is used as a constraint and the analysis criteria.

In this respect, $U$ has been previously introduced. If the matrix $F_{m}$ is constructed, then the complementary energy can be calculated below [1,21]:

$$
U_{c}=\frac{1}{2}\{R\}^{t}\left[F_{m}\right]\{R\},
$$

where $\left[F_{m}\right]$ is the unassembled flexibility matrix of the structure, and $\{R\}$ is the member force vector. For equilibrium, $U$ is negative and $U+U_{c}$ is equal to zero. The objective function in metaheuristic algorithms $f$ is selected as $f=W\left(1+\alpha\left(U+U_{c}\right)^{2}\right)$, where the first term belongs to the optimization and the second term 
Table 1. Comparison of the magnitudes of $U$.

\begin{tabular}{|c|c|c|c|c|c|c|c|c|c|c|c|}
\hline \multicolumn{3}{|c|}{$\begin{array}{c}\text { Exact } \\
\text { (force method) }\end{array}$} & \multicolumn{3}{|c|}{$\begin{array}{c}\text { Exact } \\
\text { (displacement } \\
\text { method) }\end{array}$} & \multicolumn{2}{|c|}{ CBO } & \multicolumn{2}{|c|}{ ECBO } & \multicolumn{2}{|c|}{ VPS } \\
\hline & $\boldsymbol{v}$ & $\boldsymbol{R}$ & & $v$ & $\boldsymbol{R}$ & $\boldsymbol{v}$ & $\boldsymbol{R}$ & $v$ & $\boldsymbol{R}$ & $\boldsymbol{v}$ & $\boldsymbol{R}$ \\
\hline $\mathrm{v} 8$ & 46.9856 & 6.1945 & $\mathrm{v} 1$ & 0 & 6.1945 & 0 & 6.1945 & 0 & 6.1945 & 0 & 6.1945 \\
\hline \multirow[t]{11}{*}{$\mathrm{v} 11$} & 24.9255 & 6.2682 & $\mathrm{v} 2$ & 0 & 6.2682 & 0 & 6.2682 & 0 & 6.2682 & 0 & 6.2682 \\
\hline & & -2.7988 & v3 & 0 & -2.7988 & 0 & -2.7988 & 0 & -2.7988 & 0 & -2.7988 \\
\hline & & 2.9985 & $\mathrm{v} 4$ & -8.276 & 2.9985 & -8.276 & 2.9985 & -8.276 & 2.9985 & -8.276 & 2.9985 \\
\hline & & 3.0521 & v 5 & 12.2083 & 3.0521 & 12.2083 & 3.0521 & 12.2083 & 3.0521 & 12.2083 & 3.0521 \\
\hline & & -2.7587 & v6 & -30.3131 & -2.7587 & -30.3131 & -2.7587 & -30.3131 & -2.7587 & -30.3131 & -2.7587 \\
\hline & & -3.656 & v7 & 12.389 & -3.656 & 12.389 & -3.656 & 12.389 & -3.656 & 12.389 & -3.656 \\
\hline & & 4.6647 & v8 & -46.9856 & 4.6647 & -46.9856 & 4.6647 & -46.9856 & 4.6647 & -46.9856 & 4.6647 \\
\hline & & -5.5575 & v9 & 24.2023 & -5.5575 & 24.2023 & -5.5575 & 24.2023 & -5.5575 & 24.2023 & -5.5575 \\
\hline & & 4.5978 & v10 & 0 & 4.5978 & 0 & 4.5978 & 0 & 4.5978 & 0 & 4.5978 \\
\hline & & -3.7481 & v11 & 24.9255 & -3.7481 & 24.9255 & -3.7481 & 24.9255 & -3.7481 & 24.9255 & -3.7481 \\
\hline & & & $\mathrm{v} 12$ & -8.3965 & & -8.3965 & & -8.3965 & & -8.3965 & \\
\hline \multicolumn{3}{|c|}{$U_{c}=359.5552$} & \multicolumn{3}{|c|}{$U=-359.5552$} & \multicolumn{2}{|c|}{$U=-359.5552$} & \multicolumn{2}{|c|}{$U=-359.5552$} & \multicolumn{2}{|c|}{$U=-359.5552$} \\
\hline
\end{tabular}

corresponds to the analysis, and $\alpha$ can be considered as a large number. Obviously, $f$ will ultimately approach the weight $W$ as $\left(U+U_{c}\right)^{2}$ becomes zero.

If a structure includes other constraints, then they should be normalized and added to the above function with a penalty function. Thus, the ultimate formulation of the objective function is given below:

$$
\begin{aligned}
\operatorname{Min} F(v, A)= & \left(1+\varepsilon_{1}\left(\sum_{m=1}^{n c} \max \left(0, g_{m}(A)\right)\right)\right)^{\varepsilon_{2}} \\
& W\left(1+\alpha\left(U+U_{c}\right)^{2}\right)
\end{aligned}
$$

where $g_{m}(A)$ is the sum of the violations of the design constraints. Their values can be written in the form of the absolute value of the existing value to permissible value minus one. The constant $\varepsilon_{1}$ is set equal to 1 , while $\varepsilon_{2}$ starts from 1.5 and linearly increases to 3 .

For large-scale structures, since large flexibility (or stiffness) matrices do not require a solution or inverse, the proposed method is more efficient. Instead of applying direct analysis, it is simply required to consider minimizing energy function in the proposed analysis.

\subsection{Non-simultaneous displacement method}

To make a better comparison of the results, the nonsimultaneous force method and the non-simultaneous displacement method were applied to ensure an optimal design of some truss structures. The design variables of these two methods include only cross-section $(A)$, and their objective function is given below:
$\operatorname{Min} F(A)=\left(1+\varepsilon_{1}\left(\sum_{m=1}^{n c} \max \left(0, g_{m}(A)\right)\right)\right)^{\varepsilon_{2}} W$.

In the following, the optimal design of four trusses is performed in four different cases:

- Case 1: Simultaneous displacement method. In this method, simultaneous analysis and design of trusses is performed by minimizing Eq. (4) through $\mathrm{CBO}, \mathrm{ECBO}$, and VPS algorithms. In this method, design variables and analysis variables include the cross-section of members $(A)$ and nodal displacement $(v)$, respectively.

- Case 2: Simultaneous force method. In the case of this method, Kaveh and Bijari applied CBO, ECBO, and VPS algorithms to perform simultaneous analysis and design of trusses [22]. In this method, design variables and analysis variables include the cross-section of the members $(A)$ and redundant forces $(q)$, respectively.

- Case 3: Non-simultaneous displacement method. In this method, the optimal design of trusses is achieved by minimizing Eq. (5) through CBO, ECBO, and VPS algorithms. In this method, design variables include the cross-section of the members $(A)$.

- Case 4: Non-simultaneous force method. In this method, the optimal design of trusses is achieved by minimizing Eq. (5) through CBO, ECBO, and VPS algorithms. In this method, design variables include the cross-section of the members $(A)$. 


\section{Examples}

\subsection{Example 1: A 10-bar planar truss}

Optimal design of a 10-bar planar truss, shown in Figure 2, is considered. Table 2 contains the data concerning the design of this truss. This structure has 8 degrees of kinematical indeterminacy. The obtained results are shown in Table 3 . Figure 3 shows the comparison of the values of weight obtained by four different methods. It can be seen that the minimum value has been obtained by the simultaneous displacement method using CBO algorithm (5061.7 lb) as compared to the values obtained by the other three methods and the ones in the literature ([23] (5095.46 $\mathrm{lb})$ and [1] $(5061.9 \mathrm{lb}))$. In this structure, the nonsimultaneous force method has outperformed the nonsimultaneous displacement method. Figure 4 shows the comparison of convergence histories for CBO, ECBO, and VPS algorithms by the simultaneous displacement method. It can be seen that the CBO algorithm has converged at fewer iterations than other algorithms and achieved better results.

\subsection{Example 2: A 25-bar spatial truss}

Figure 5 shows the schematic of a spatial truss and its members grouping. Table 4 provides the necessary

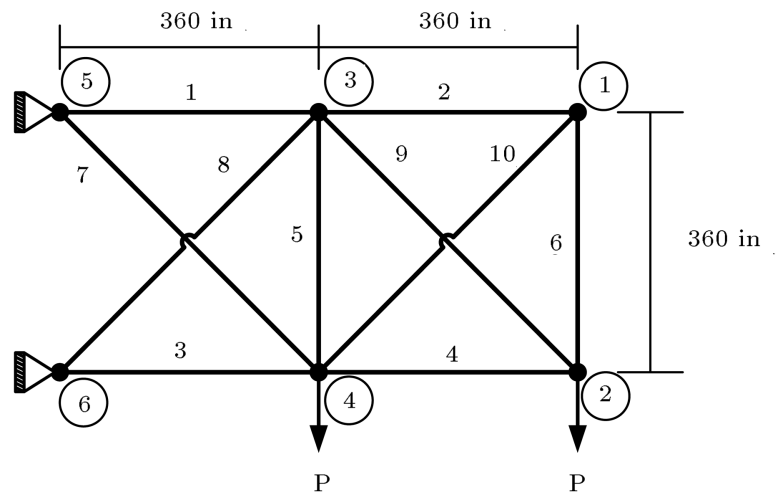

Figure 2. Geometry of a 10-bar planar truss.

Table 2. Design data for the 10-bar planar truss.

\begin{tabular}{l}
\hline Design and analysis variables in simultaneous displacement method \\
\hline Variables: $A_{1} ; A_{2} ; A_{3} ; A_{4} ; A_{5} ; A_{6} ; A_{7} ; A_{8} ; A_{9} ; A_{10} ; v_{1} ; v_{2} ; v_{3} ; v_{4} ; v_{5} ; v_{6} ; v_{7} ; v_{8}$ \\
\hline Material property and constraint data \\
\hline Elastic modulus: $E=1 e 7 \mathrm{psi}=6.895 \mathrm{e} \mathrm{MPa}$ \\
Material density: $\rho=0.1 \mathrm{lb} / \mathrm{in}^{3}=0.00277 \mathrm{~kg} / \mathrm{cm}^{3}$ \\
\hline Stress constraints \\
\hline$\left|\sigma_{i}\right| \leq 25 \mathrm{ksi}(172.375 \mathrm{MPa}) ; i=1, \ldots, 10$ \\
\hline Nodal displacement constraint in all directions of the coordinated system \\
\hline$\left|\Delta_{i}\right| \leq 2$ in $(5.08 \mathrm{~cm}) ; i=1, \ldots, 6$ \\
\hline List of the available profiles \\
\hline$A_{i} \geq 0.1 \mathrm{in}^{2}\left(0.6452 \mathrm{~cm}^{2}\right) ; i=1, \ldots, 10$ \\
\hline
\end{tabular}

Table 3. Comparison of optimal design for the 10-bar planar truss.

\begin{tabular}{|c|c|c|c|c|c|c|c|c|c|c|c|c|}
\hline \multirow[b]{2}{*}{$\begin{array}{l}\text { Area } \\
\left(\mathrm{in}^{2}\right)\end{array}$} & \multicolumn{3}{|c|}{$\begin{array}{c}\text { Simultaneous } \\
\text { force }[22]\end{array}$} & \multicolumn{3}{|c|}{$\begin{array}{c}\text { Non-simultaneous } \\
\text { force }\end{array}$} & \multicolumn{3}{|c|}{$\begin{array}{l}\text { Simultaneous } \\
\text { displacement }\end{array}$} & \multicolumn{3}{|c|}{$\begin{array}{c}\text { Non-simultaneous } \\
\text { displacement }\end{array}$} \\
\hline & CBO & ECBO & VPS & CBO & ECBO & VPS & CBO & ECBO & VPS & CBO & ECBO & VPS \\
\hline A1 & 30.8439 & 31.5033 & 30.3 & 30.5959 & 29.164 & 30.5118 & 30.8548 & 29.9953 & 31.3807 & 30.5236 & 30.1275 & 30.582 \\
\hline A2 & 0.1 & 0.1 & 0.1 & 0.1 & 0.1 & 0.1026 & 0.1001 & 0.1 & 0.1015 & 0.1361 & 0.1 & 0.1207 \\
\hline A3 & 23.6834 & 22.5822 & 23.3 & 23.0586 & 23.0336 & 23.5 & 23.1646 & 23.0366 & 22.9111 & 22.9757 & 23.4931 & 24.2501 \\
\hline A4 & 15.2329 & & & & & & & & & 14.9044 & & \\
\hline A5 & 0.1 & 0.1 & 0.1 & 0.1 & 0.1011 & 0.1019 & 0.1 & 0.1 & 0.1053 & 0.1 & 0.1 & 0.1012 \\
\hline A6 & 0.522 & 0.4634 & 0.5 & 0.5896 & 0.5226 & 0.5863 & 0.5755 & 0.5356 & 0.463 & 0.5721 & 0.6709 & 0.6636 \\
\hline A 7 & 7.4652 & 7.5275 & 7.4 & 7.5305 & 7.5215 & 7.4372 & 7.4267 & 7.4626 & 7.5761 & 7.5881 & 7.4276 & 7.4104 \\
\hline A 8 & 20.9774 & 20.6941 & 21 & 21.0923 & & & 20.6799 & 21.1664 & 21.3159 & 21.4434 & 20.7521 & 20.9994 \\
\hline A9 & 21.0875 & 21.1023 & 21.8 & 21.4561 & 21.9553 & 21.7535 & 21.847 & 22.1978 & 21.3952 & 21.4369 & 21.1649 & 20.861 \\
\hline A10 & 0.1 & & 0.1 & 0.1 & 0.1 & 0.1033 & 0.1 & 0.1 & 0.1014 & 0.1 & 0.1 & 0.102 \\
\hline Weight (lb) & 5064.1 & 5066.6 & 5063.6 & 5063.5 & 5066.4 & 5064.5 & 5061.7 & 5062.9 & 5066.9 & 5066.2 & 5066.7 & 5068.9 \\
\hline
\end{tabular}




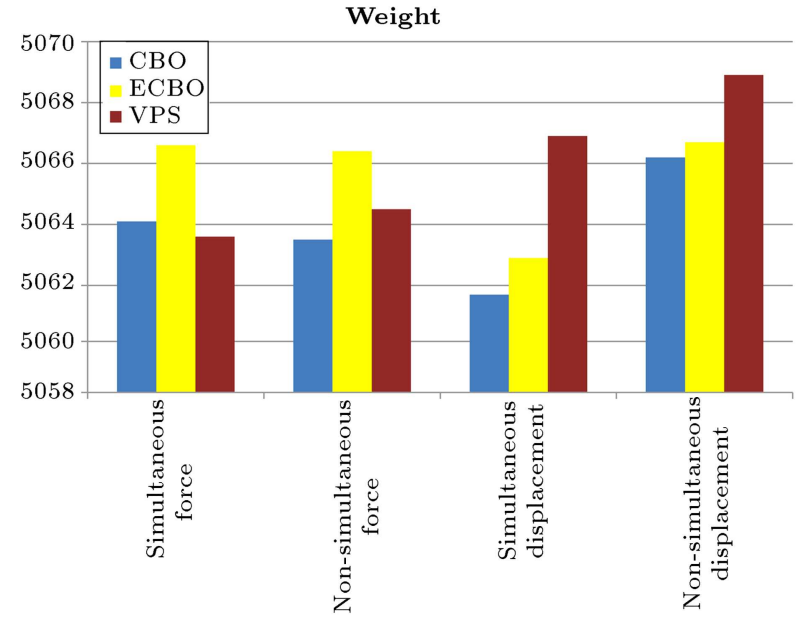

Figure 3. The comparison of the obtained values of weight for the 10-bar planar truss.

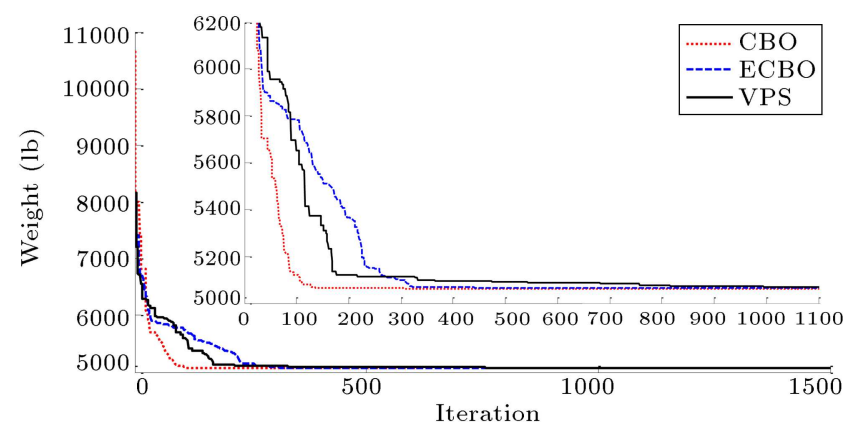

Figure 4. Convergence curves obtained for the 10-bar planar truss by simultaneous displacement method.

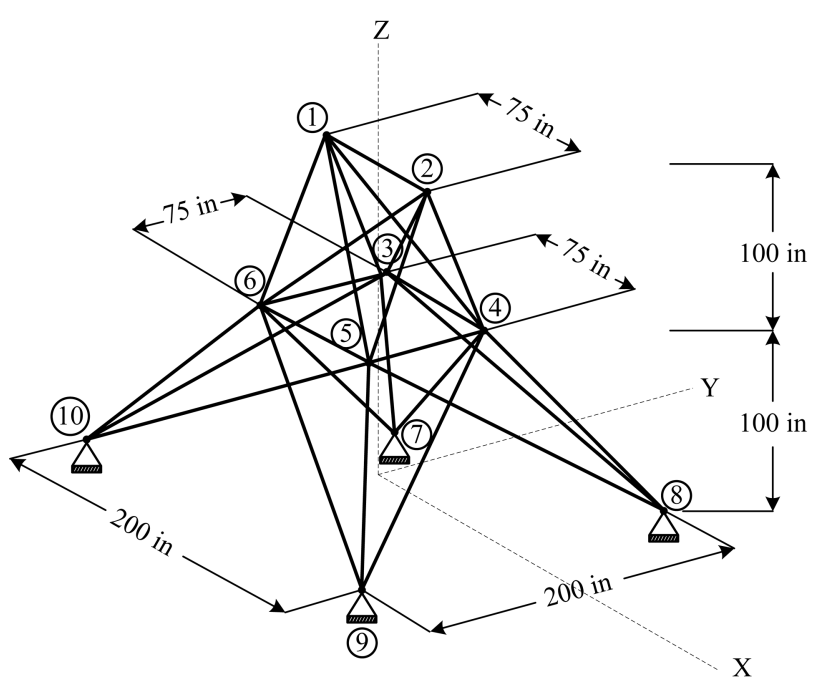

Figure 5. Schematic of a 25-bar spatial truss and grouping of the members.

data for designing this truss. This structure has 18 degrees of kinematical indeterminacy. The optimal values of the design variables and their comparison are given in Table 5. The comparison of the obtained values of weight in four various methods is shown in

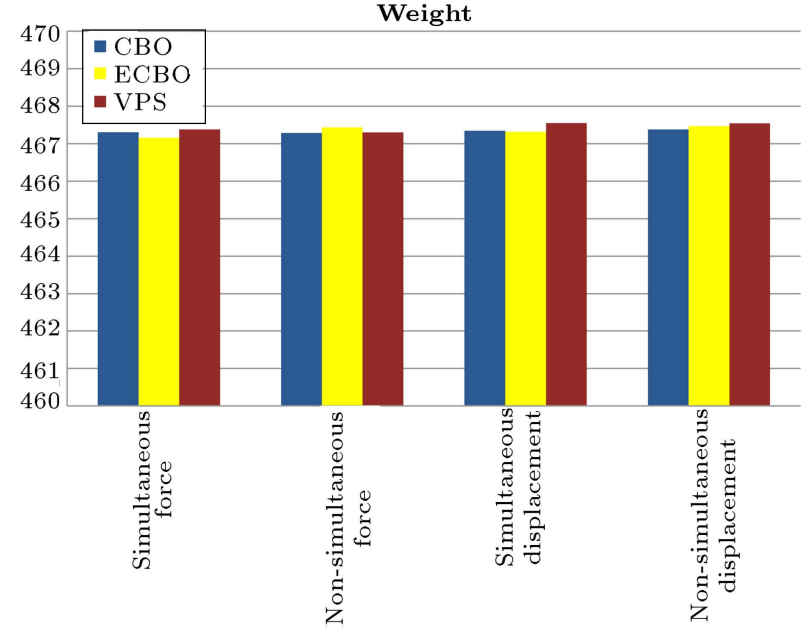

Figure 6. The comparison of the obtained values of weight for the 25-bar spatial truss.

Figure 6. The simultaneous displacement method by all the three algorithms has achieved acceptable results similar to other methods and, yet, not as favorable as the results found in the literature ([1] (467.629 lb) and [24] (467.746 lb)). The non-simultaneous force method and the non-simultaneous displacement method have achieved almost the same results. Figure 7 illustrates the comparison of the convergence histories for $\mathrm{CBO}$, ECBO, and VPS algorithms using the simultaneous displacement method. Obviously, all of the three algorithms have shown the same trend.

\subsection{Example 3: A 72-bar spatial truss}

The schematic of a 72-bar spatial truss is shown in Figure 8 as the third design example. The necessary data for the design and constraints are shown in Table 6. This structure has 48 degrees of kinematical indeterminacy. The elements are divided into sixteen groups using symmetry as follows:
(1) $A_{1}-A_{4}$
(2) $A_{5}-A_{12}$,
(3) $A_{13}-A_{16}$
(4) $A_{17}-A_{18}$,
(5) $A_{19}-A_{22}$,
(6) $A_{20}-A_{30}$,
(7) $A_{31}-A_{34}$
(8) $A_{35}-A_{36}$,
(9) $A_{37}-A_{40}$,
(10) $A_{41}-A_{48}$,
(11) $A_{49}-A_{52}$,
(13) $A_{55}-A_{58}$,
(12) $A_{53}-A_{54}$,
(14) $A_{59}-A_{62}$,
(15) $A_{63}-A_{70}$,
(16) $A_{71}-A_{72}$.

The structure is subjected to the two load cases, as shown in Table 7 . Table 8 compares the results obtained by CBO, ECBO, and VPS algorithms with those of other optimization methods. The comparison of the obtained weight values by four various methods is shown in Figure 9. It can be seen that the CBO and ECBO algorithms using the simultaneous displacement method have achieved better results $(384.43 \mathrm{lb}$, $382.2287 \mathrm{lb}$ ) than the other three methods and not as 


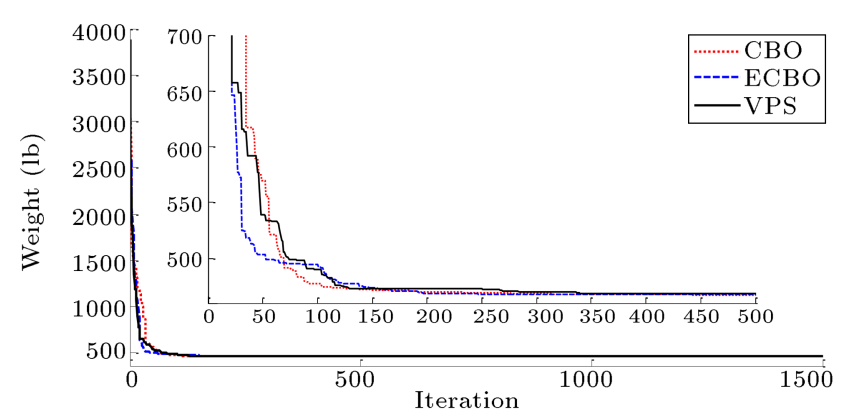

Figure 7. Convergence curves obtained for the 25-bar spatial truss by simultaneous displacement method.

acceptable as the results found in the literature ([25] $(392.8483 \mathrm{lb}))$. The non-simultaneous force method (382.663 lb, $383.3211 \mathrm{lb})$ and the non-simultaneous displacement method (385.4571 lb, $384.1302 \mathrm{lb}$ ) have achieved optimized weights close to each other by CBO and ECBO algorithms. The corresponding convergence curves are compared in the case of the simultaneous displacement method, shown in Figure 10. As is clear, the ECBO algorithm has obtained better results at fewer iterations.

\subsection{Example 4: A 120-bar dome truss}

A 120-bar dome structure is considered as the fourth design example. Geometry and member grouping structures are shown in Figure 11. This structure has 111 degrees of kinematical indeterminacy. The necessary data for the design and the constraints are shown in Table 9. The loading condition is considered as follows:

1. Vertical load at node 1 equal to -13.49 kips $(-60$ $\mathrm{kN})$.

Table 4. Member grouping of the 25-bar spatial truss.

\begin{tabular}{cc}
\hline Group number & Members \\
\hline 1 & $1-2$ \\
2 & $1-4,2-3,1-5,2-6$ \\
3 & $2-5,2-4,1-3,1-6$ \\
4 & $3-6,4-5$ \\
5 & $3-4,5-6$ \\
6 & $3-10,6-7,4-9,5-8$ \\
7 & $3-8,4-7,6-9,5-10$ \\
8 & $3-7,4-8,5-9,6-10$ \\
\hline
\end{tabular}

Design and analysis variables in simultaneous displacement method

\begin{tabular}{|c|c|c|c|}
\hline \multicolumn{4}{|c|}{ Material property and constraint data } \\
\hline \multicolumn{4}{|c|}{ Elastic modulus: $E=1 e 7 \mathrm{psi}=6.895 e 7 \mathrm{MPa}$} \\
\hline \multicolumn{4}{|c|}{ Material density: $\rho=0.1 \mathrm{lb} / \mathrm{in}^{3}=0.00277 \mathrm{~kg} / \mathrm{cm}^{3}$} \\
\hline \multicolumn{4}{|c|}{ Stress constraints } \\
\hline \multicolumn{4}{|c|}{$\left|\sigma_{i}\right| \leq 40 \mathrm{ksi}(275.8 \mathrm{MPa}) ; i=1, \ldots, 25$} \\
\hline \multicolumn{4}{|c|}{ Displacement constraint in the directions of $X$ and $Y$ in the coordinated system } \\
\hline \multicolumn{4}{|c|}{$\left|\Delta_{i}\right| \leq 0.35$ in $(0.8890 \mathrm{~cm}) ; i=1,2$} \\
\hline \multicolumn{4}{|c|}{ List of the available profiles } \\
\hline \multicolumn{4}{|c|}{ Continuous sections } \\
\hline \multicolumn{4}{|c|}{$A_{i} \geq 0.1 \mathrm{in}^{2}\left(0.6452 \mathrm{~cm}^{2}\right)$} \\
\hline \multicolumn{4}{|c|}{ Loading data } \\
\hline Node & Px: kips $(\mathrm{kN})$ & Py: kips $(\mathrm{kN})$ & Pz: kips $(\mathrm{kN})$ \\
\hline 1 & $1(4.448)$ & $-10(-44.48)$ & $-10(-44.48)$ \\
\hline 2 & 0 & $-10(-44.48)$ & $-10(-44.48)$ \\
\hline 3 & $0.5(2.224)$ & $0 \quad 0$ & 0 \\
\hline 6 & $0.6(2.6688)$ & 0 & 0 \\
\hline
\end{tabular}


Table 5. Comparison of the optimal designs for the 25-bar spatial truss.

\begin{tabular}{|c|c|c|c|c|c|c|c|c|c|c|c|c|}
\hline \multirow[t]{2}{*}{$\begin{array}{l}\text { Area } \\
\left(\mathrm{in}^{2}\right)\end{array}$} & \multicolumn{3}{|c|}{$\begin{array}{c}\text { Simultaneous force, } \\
\text { Kaveh and } \\
\text { bijari [22] }\end{array}$} & \multicolumn{3}{|c|}{$\begin{array}{l}\text { Non-simultaneous } \\
\text { force }\end{array}$} & \multicolumn{3}{|c|}{$\begin{array}{l}\text { Simultaneous } \\
\text { displacement }\end{array}$} & \multicolumn{3}{|c|}{$\begin{array}{l}\text { Non-simultaneous } \\
\text { displacement }\end{array}$} \\
\hline & CBO & ECBO & VPS & CBO & ECBO & VPS & $\mathrm{CBO}$ & ECBO & VPS & $\mathrm{CBO}$ & ECBO & VPS \\
\hline A1 & 0.1 & 0.1 & 0.1169 & 0.1 & 0.1 & 0.1044 & 0.1011 & 0.1004 & 0.108 & 0.1 & 0.1014 & 0.1152 \\
\hline A2 & 0.1029 & 0.1 & 0.1038 & 0.1 & 0.1032 & 0.1024 & 0.1012 & 0.1 & 0.1037 & 0.1 & 0.1 & 0.104 \\
\hline A3 & 3.5539 & 3.5683 & 3.6151 & 3.5787 & 3.5368 & 3.6369 & 3.5923 & 3.6006 & 3.5775 & 3.594 & 3.6633 & 3.5906 \\
\hline A4 & 0.1056 & 0.1 & 0.1012 & 0.1021 & 0.1 & 0.1013 & 0.1 & 0.1 & 0.105 & 0.1 & 0.1 & 0.1007 \\
\hline A5 & 1.9539 & 1.9592 & 1.9546 & 1.8869 & 1.9402 & 1.9522 & 1.9663 & 1.9577 & 2.0431 & 1.8937 & 1.9855 & 1.9371 \\
\hline A 6 & 0.7876 & 0.7893 & 0.7857 & 0.7742 & 0.7827 & 0.772 & 0.7893 & 0.7704 & 0.7777 & 0.7805 & 0.7611 & 0.7742 \\
\hline A 7 & 0.1499 & 0.1461 & 0.1325 & 0.1452 & 0.1256 & 0.1675 & 0.1461 & 0.1497 & 0.1351 & 0.1495 & 0.1333 & 0.1548 \\
\hline A8 & 3.9437 & 3.9354 & 3.9202 & 3.9709 & 4.0047 & 3.876 & 3.9163 & 3.9336 & 3.9362 & 3.9447 & 3.9133 & 3.9333 \\
\hline Weight (lb) & 467.304 & 467.16 & 467.382 & 467.290 & 467.439 & 467.303 & 467.349 & 467.322 & 467.55 & 467.38 & 467.47 & 467.542 \\
\hline
\end{tabular}

Table 6. Design data for the 72-bar spatial truss.

\begin{tabular}{l}
\hline Design and analysis variables in simultaneous displacement method \\
\hline Variables: $A_{1} ; A_{2} ; \ldots ; A_{16} ; v_{1} ; v_{2} ; \ldots ; v_{48}$ \\
\hline Material property and constraint data \\
\hline Elastic modulus: $E=1 e 7 \mathrm{psi}=6.895 \mathrm{e} \mathrm{MPa}$ \\
Material density: $\rho=0.1 \mathrm{lb} / \mathrm{in}^{3}=0.00277 \mathrm{~kg} / \mathrm{cm}^{3}$ \\
\hline Stress constraints \\
\hline$\left|\sigma_{i}\right| \leq 25 \mathrm{ksi}(172.37 \mathrm{MPa}) ; i=1, \ldots, 72$ \\
\hline Displacement constraint in the directions of $X$ and $Y$ in the coordinated system \\
\hline$\left|\Delta_{i}\right| \leq 0.25$ in $(0.635 \mathrm{~cm}) ; i=1,2,3,4$ \\
\hline List of the available profiles \\
\hline$A_{i} \geq 0.1 \mathrm{in}^{2}\left(0.6452 \mathrm{~cm}^{2}\right)$ \\
\hline
\end{tabular}
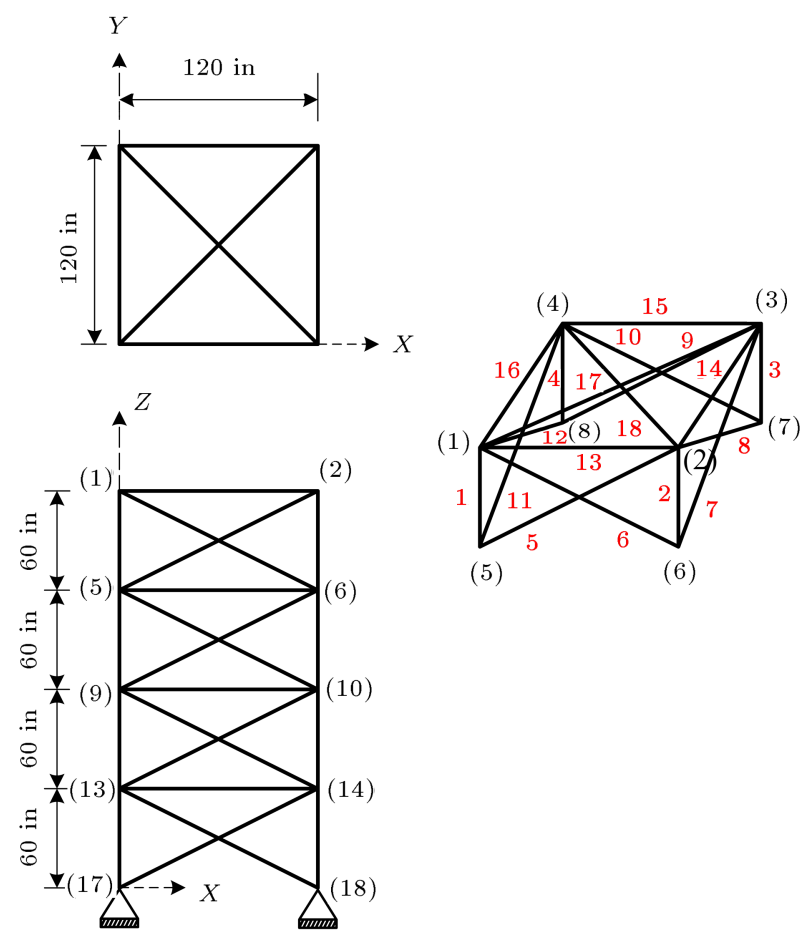

Figure 8. Schematic of a 72-bar spatial truss.
2. Vertical loads at nodes $2-14$ equal to -6.744 kips $(-30 \mathrm{kN})$.

3. Vertical loads in the rest of the nodes equal to 2.248 kips $(-10 \mathrm{kN})$.

The comparison of the optimal designs of 120-bar

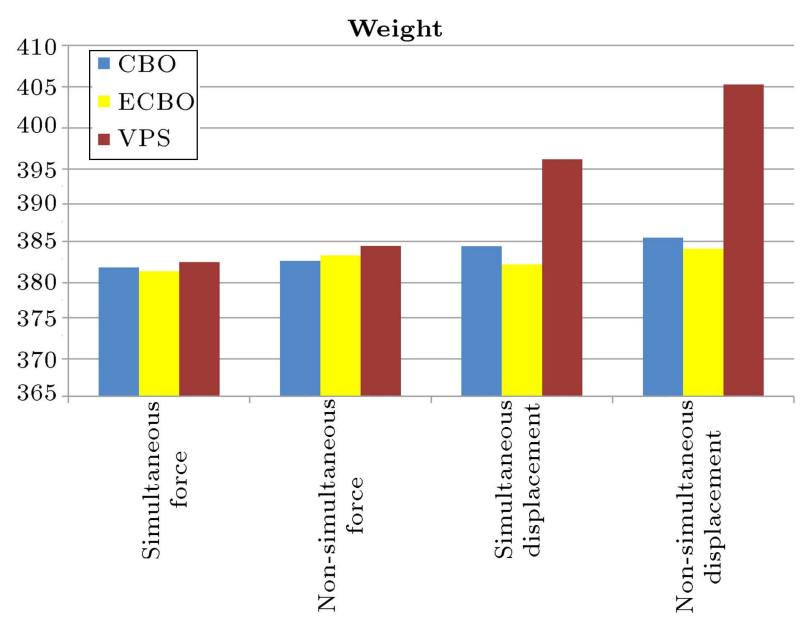

Figure 9. The comparison of the obtained values of weight for the 72-bar spatial truss. 
Table 7. Loading conditions for the 72-bar spatial truss.

\begin{tabular}{cccccccc}
\hline & \multicolumn{3}{c}{ Load Case 1 } & & \multicolumn{3}{c}{ Load Case 2 } \\
\cline { 2 - 4 } \cline { 6 - 7 } Nodes & Px (kips) & Py (kips) & Pz (kips) & & Px (kips) & Py (kips) & Pz (kips) \\
\hline $\mathbf{1}$ & 5 & 5 & -5 & & 0 & 0 & -5 \\
$\mathbf{2}$ & 0 & 0 & 0 & & 0 & 0 & -5 \\
$\mathbf{3}$ & 0 & 0 & 0 & & 0 & 0 & -5 \\
$\mathbf{4}$ & 0 & 0 & 0 & & 0 & 0 & -5 \\
\hline
\end{tabular}

Table 8. Comparison of the optimal designs for the 72-bar spatial truss.

\begin{tabular}{|c|c|c|c|c|c|c|c|c|c|c|c|c|}
\hline \multirow[t]{2}{*}{$\begin{array}{l}\text { Area } \\
\left(\mathrm{in}^{2}\right)\end{array}$} & \multicolumn{3}{|c|}{$\begin{array}{l}\text { Simultaneous } \\
\text { force }[22]\end{array}$} & \multicolumn{3}{|c|}{$\begin{array}{c}\text { Non- } \\
\text { simultaneous } \\
\text { force }\end{array}$} & \multicolumn{3}{|c|}{$\begin{array}{l}\text { Simultaneous } \\
\text { displacement }\end{array}$} & \multicolumn{3}{|c|}{$\begin{array}{c}\text { Non- } \\
\text { simultaneous } \\
\text { displacement }\end{array}$} \\
\hline & CBO & ECBO & VPS & $\mathrm{CBO}$ & ECBO & VPS & CBO & ECBO & VPS & CBO & ECBO & VPS \\
\hline A1 & 1.9 & 2.0364 & 1.9501 & 1.9732 & 1.8881 & 1.9931 & 1.897 & 1.8368 & 2.1025 & 1.9422 & 2.1589 & 1.2837 \\
\hline A2 & 0.5125 & 0.51 & 0.4888 & 0.4913 & 0.4745 & 0.5234 & 0.5201 & 0.5242 & 0.5283 & 0.5084 & 0.4819 & 0.4419 \\
\hline A3 & 0.1 & 0.1 & 0.1001 & 0.1 & 0.1 & 0.106 & 0.1259 & 0.1001 & 0.143 & 0.106 & 0.1019 & 0.137 \\
\hline A4 & 0.1 & 0.1 & 0.1168 & 0.1038 & 0.1148 & 0.1096 & 0.1163 & 0.1 & 0.11 & 0.1 & 0.1 & 0.1272 \\
\hline A5 & 1.2155 & 1.4082 & 1.3009 & 1.3184 & 1.2655 & 1.2909 & 1.1794 & 1.19 & 1.3707 & 1.2192 & 1.1595 & 1.3388 \\
\hline A 6 & 0.5303 & 0.505 & 0.5048 & 0.5237 & 0.5242 & 0.5016 & 0.478 & 0.5039 & 0.578 & 0.5947 & 0.5402 & 0.6259 \\
\hline A 7 & 0.1 & 0.1003 & 0.1113 & 0.1022 & 0.1 & 0.1222 & 0.101 & 0.1065 & 0.1271 & 0.1089 & 0.1 & 0.1199 \\
\hline A 8 & 0.1054 & 0.1 & 0.115 & 0.1 & 0.1 & 0.124 & 0.105 & 0.1 & 0.103 & 0.1084 & 0.1 & 0.1077 \\
\hline A9 & 0.5168 & 0.5404 & 0.5015 & 0.556 & 0.6301 & 0.5079 & 0.6433 & 0.6047 & 0.4356 & 0.6837 & 0.5528 & 0.5163 \\
\hline A10 & 0.5063 & 0.4598 & 0.5184 & 0.5383 & 0.5256 & 0.5289 & 0.5446 & 0.5346 & 0.448 & 0.4732 & 0.4834 & 0.6188 \\
\hline A11 & 0.1 & 0.1 & 0.1112 & 0.1023 & 0.1 & 0.1034 & 0.1 & 0.1 & 0.108 & 0.1 & 0.1003 & 0.1554 \\
\hline A12 & 0.1095 & 0.1 & 0.1034 & 0.1 & 0.1 & 0.1046 & 0.1 & 0.1794 & 0.2298 & 0.1 & 0.1256 & 0.2858 \\
\hline A13 & 0.169 & 0.1544 & 0.1552 & 0.1737 & 0.1678 & 0.1627 & 0.1634 & 0.1539 & 0.1638 & 0.1616 & 0.16 & 0.157 \\
\hline A14 & 0.5567 & 0.5369 & 0.5545 & 0.5211 & 0.5246 & 0.5543 & 0.5691 & 0.5423 & 0.5683 & 0.4929 & 0.5032 & 0.6363 \\
\hline A15 & 0.4301 & 0.4365 & 0.4203 & 0.379 & 0.424 & 0.3019 & 0.4166 & 0.4147 & 0.2506 & 0.4829 & 0.5401 & 0.5002 \\
\hline A16 & 0.5561 & 0.6062 & 0.5854 & 0.6005 & 0.6814 & 0.6297 & 0.5297 & 0.5286 & 0.7493 & 0.5436 & 0.5984 & 0.453 \\
\hline
\end{tabular}

Weight (lb) 381.8569381 .3952382 .4935382 .663383 .3211384 .452384 .4343382 .2287396 .2091385 .4571384 .1302405 .2607

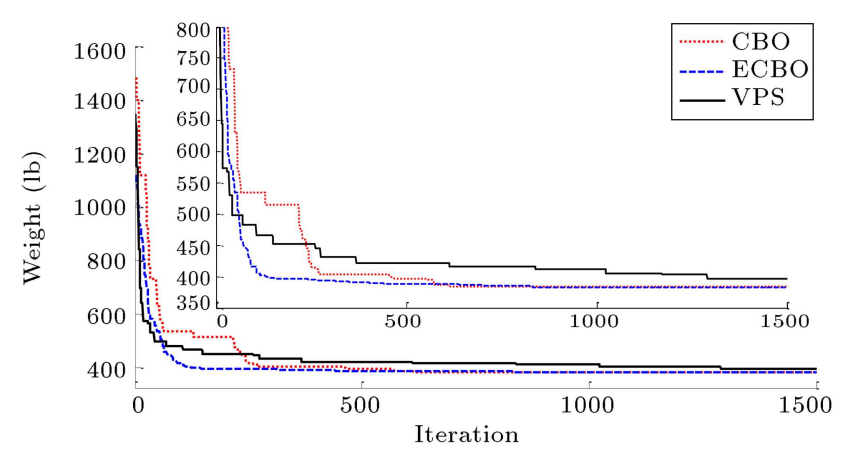

Figure 10. Convergence curves obtained for the 72-bar spatial truss by simultaneous displacement method.

dome truss is shown in Table 10. Figure 12 presents the comparison of the obtained weight values by four different methods. In the simultaneous displacement method, the obtained weight values by all the three algorithms are lower than those found in the literature ([24] (33241.99 lb)) and, also, the optimized weight by ECBO algorithm (31886 lb) is well consistent with the values obtained by the simultaneous force method and the non-simultaneous force method. The weight obtained by VPS algorithm using the non-simultaneous displacement method $(31888 \mathrm{lb})$ is very close to that found by the non-simultaneous force method. Figure 13 shows the comparison of the convergence curves of the best results obtained by CBO, ECBO, and VPS algorithms using the simultaneous displacement method. It appears that the CBO algorithm has converged at fewer iterations; however, the ECBO algorithm has achieved better results.

\section{Concluding remarks}

In this paper, an efficient method was proposed to 
Table 9. Design data for the 120-bar spatial truss.

\begin{tabular}{l} 
Design and analysis variables in simultaneous displacement method \\
\hline Variables: $A_{1} ; A_{2} ; A_{3} ; A_{4} ; A_{5} ; A_{6} ; A_{7} ; v_{1} ; v_{2} ; \ldots ; v_{111}$ \\
\hline Material property and constraint data \\
\hline Elastic modulus: $E=30450 \mathrm{Ksi}=210000 \mathrm{MPa}$ \\
Material density: $\rho=0.288 \mathrm{lb} / \mathrm{in}^{3}=7971.810 \mathrm{~kg} / \mathrm{cm}^{3}$ \\
For all members: $\quad 0.775 \leq A_{i} \leq 20 \mathrm{in}^{2}, \quad i=1, \ldots, 120$ \\
\hline Constraints \\
$\lambda_{i}=\frac{L_{i}}{r}, \quad r=\sqrt{0.4 \times A}, \quad C_{c}=\sqrt{\frac{2 \pi^{2} E}{F_{y}}}$ \\
\hline
\end{tabular}

For tensile members

$\lambda_{i} \leq 300$

$F_{a} \leq 0.6 F_{y}$

For compressive members

$\lambda_{i} \leq 200$

$F_{a}=\frac{\left[\left(1-\frac{\lambda_{i}}{2 C_{c}^{2}}\right) F_{y}\right]}{\left(\frac{5}{3}+\frac{3 \lambda_{i}}{8 C_{c}}-\frac{\lambda_{i}^{3}}{8 C_{c}^{3}}\right)}$ for $\lambda_{i} \leq C_{c}$

$F_{a}=\frac{12 \pi^{2} E}{23 \lambda_{i}^{2}}$ for $\lambda_{i}>C_{c}$

$\left|\sigma_{i}\right| \leq 58 \mathrm{ksi}(400 \mathrm{MPa}) ; i=1, \ldots, 120$

Displacement constraint in the directions of $X, Y$ and $Z$ at all unsupported nodes $\left|\Delta_{i}\right| \leq 0.1969$ in $(0.500126 \mathrm{~cm})$

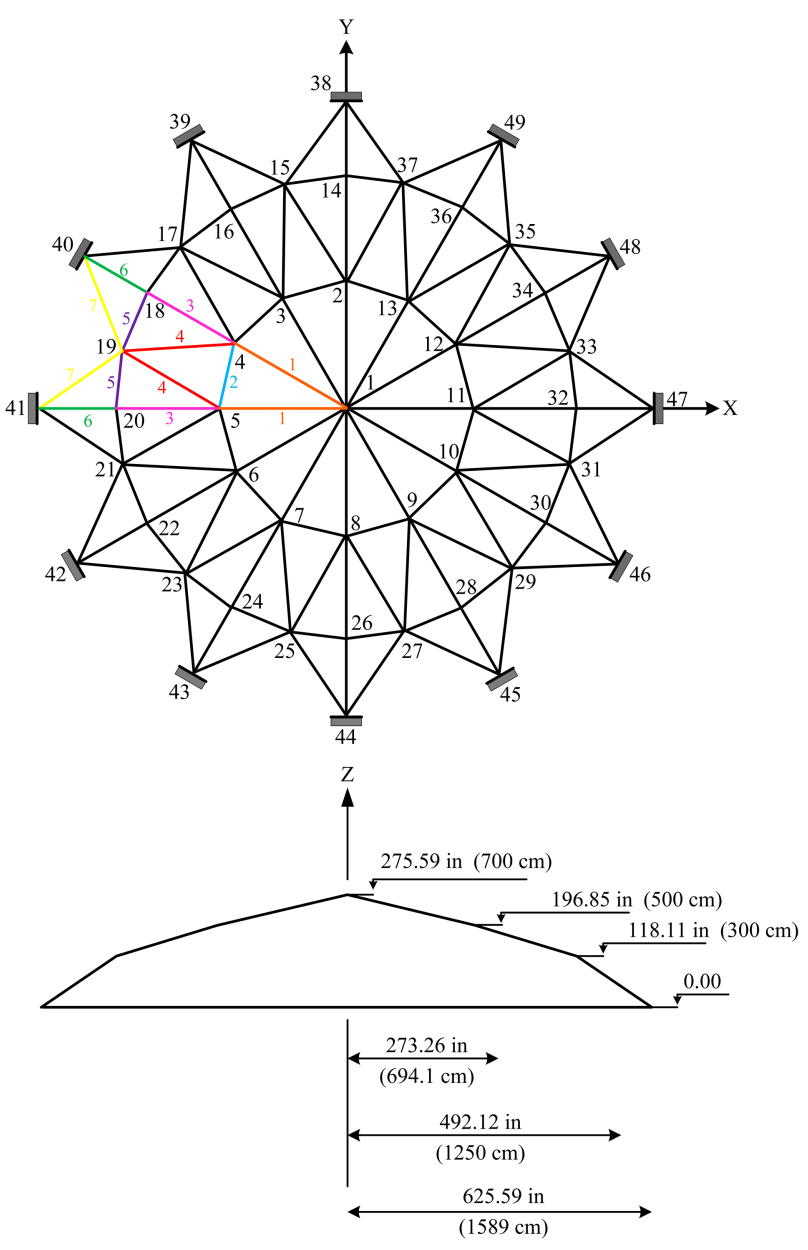

Figure 11. Schematic of a 120-bar dome truss.

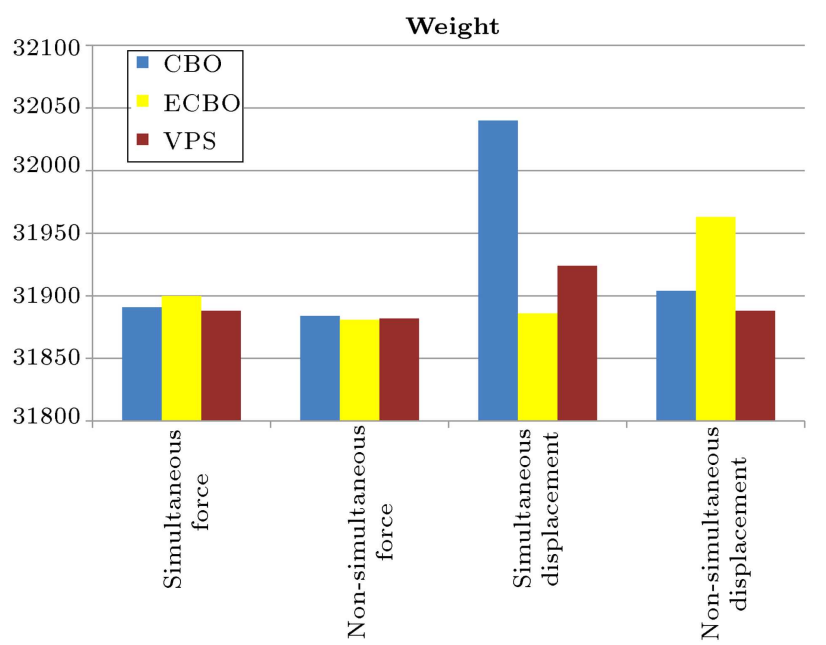

Figure 12. The comparison of the obtained values of weight for the 120-bar spatial truss.

perform simultaneous analysis, design, and optimization of structures using CBO, ECBO, and VPS algorithms to prevent the formation of the inverse for large structural matrices, especially for structures with a large number of members. These metaheuristic algorithms and the displacement method were applied simultaneously to analyze and design different kinds of large-scale structures. The results were compared with those of the non-simultaneous force method and non-simultaneous displacement method. Benchmark problems were studied in order to show the performance of the presented method. The proposed tech- 
Table 10. Comparison of the optimal designs for the 120-bar spatial truss.

\begin{tabular}{|c|c|c|c|c|c|c|c|c|c|c|c|c|}
\hline \multirow[t]{2}{*}{$\begin{array}{l}\text { Area } \\
\left(\mathrm{in}^{2}\right)\end{array}$} & \multicolumn{3}{|c|}{$\begin{array}{l}\text { Simultaneous } \\
\text { force }[22]\end{array}$} & \multicolumn{3}{|c|}{$\begin{array}{c}\text { Non- } \\
\text { simultaneous } \\
\text { force }\end{array}$} & \multicolumn{3}{|c|}{$\begin{array}{l}\text { Simultaneous } \\
\text { displacement }\end{array}$} & \multicolumn{3}{|c|}{$\begin{array}{c}\text { Non- } \\
\text { simultaneous } \\
\text { displacement }\end{array}$} \\
\hline & CBO & ECBO & VPS & $\mathrm{CBO}$ & ECBO & VPS & CBO & ECBO & VPS & $\mathrm{CBO}$ & ECBO & VPS \\
\hline A1 & 2.2464 & 2.2464 & 2.2464 & 2.2467 & 2.2464 & 2.2464 & 2.2464 & 2.2464 & 2.2464 & 2.2464 & 2.2464 & 2.2484 \\
\hline A2 & 15.5525 & 16.2165 & 15.773 & 15.8858 & 15.8881 & 15.8754 & 14.1522 & 15.7986 & 15.3539 & 15.7155 & 14.9285 & 15.6998 \\
\hline A3 & 5.6267 & 5.3103 & 5.3939 & 5.4508 & 5.4588 & 5.4958 & 5.9965 & 5.5503 & 5.5287 & 5.5605 & 5.44 & 5.5094 \\
\hline A4 & 2.4648 & 2.4548 & 2.467 & 2.4657 & 2.4622 & 2.4621 & 2.4688 & 2.4631 & 2.4857 & 2.4697 & 2.4726 & 2.462 \\
\hline A5 & 9.0497 & 8.9467 & 8.946 & 8.9 & 8.9038 & 8.9481 & 9.2361 & 8.9568 & 8.9281 & 8.8069 & 9.1947 & 9.0078 \\
\hline A 6 & 3.5581 & 3.4806 & 3.721 & 3.5697 & 3.5657 & 3.5199 & 3.7272 & 3.5267 & 3.7868 & 3.6676 & 4.1139 & 3.5198 \\
\hline A 7 & 1.9181 & 1.9782 & 1.959 & 1.9779 & 1.9748 & 1.9538 & 2.0818 & 1.9435 & 2.0058 & 1.9978 & 1.9449 & 1.9701 \\
\hline Weight (lb) & 31891 & 31900 & 31888 & 31884 & 31881 & 31882 & 32040 & 31886 & 31924 & 31904 & 31963 & 31888 \\
\hline
\end{tabular}

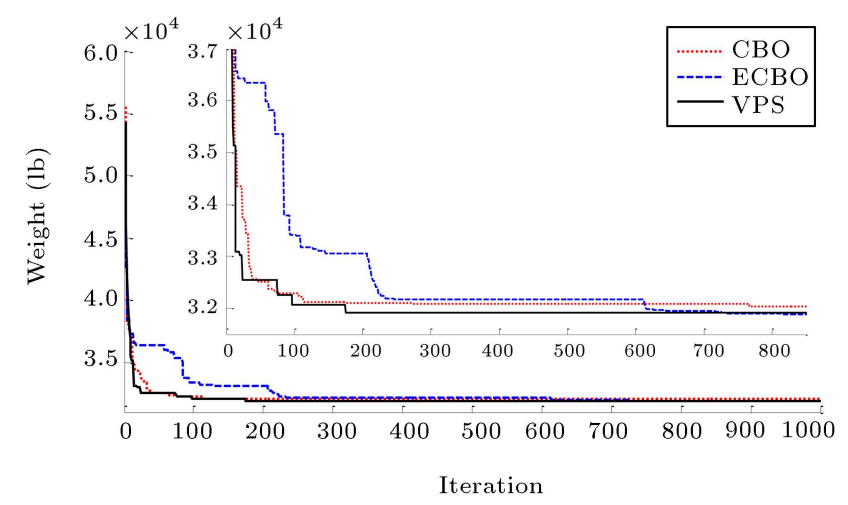

Figure 13. Convergence curves obtained for the 120-bar spatial truss by simultaneous displacement method.

nique performs better optimal designs for three of the four problems investigated than the simultaneous force method, the non-simultaneous force method, and the non-simultaneous displacement method. The results demonstrate the capability and accuracy of the metaheuristic algorithms and displacement method when simultaneously utilized for the analysis, design, and optimization of constrained problems. The comparison of the optimal designs using this work and those of the other researchers is shown in Tables 3, 5, 8, and 10 .

\section{References}

1. Kaveh, A. and Rahami, H. "Analysis, design and optimization of structures using force method and genetic algorithm", Int. J. Numer. Methods Eng., 65, pp. 1570-1584 (2016).

2. Kaveh, A. and Ilchi Ghazaan, M. "Vibrating particles system algorithm for truss optimization with multiple natural frequency constraints", Acta Mech., 228(1), pp. 307-322 (2017).

3. Holland, J.H., Adaptation in Natural and Artificial Systems, Ann Arbor: University of Michigan Press, Ann Arbor, MI, USA (1975).
4. Eberhart, R.C. and Kennedy, J. "A new optimizer using particle swarm theory", In: Proceedings of the Sixth International Symposium on Micro Machine and Human Science, Nagoya, Japan (1995).

5. Dorigo, M., Maniezzo, V., and Colorni, A. "The ant system: optimization by a colony of cooperating agents", IEEE Trans. Syst. Man, Cybernet.; Part B, 26, pp. 29-41 (1996).

6. Geem, Z.W., Joong, H.K., and Loganathan, G.V. "A new heuristic optimization algorithm: harmony search", Simul., 76(2), pp. 60-68 (2001).

7. Erol, O.K. and Eksin, I. "New optimization method: big bang-big crunch", Adv. Eng. Softw., 37, pp. 106111 (2006).

8. Yang, X.S., Nature-Inspired Metaheuristic Algorithms, 2nd edition. Forme: Luniver Press (2010).

9. Kaveh, A., Motie Share, M.A., and Moslehi, M. "A new meta-heuristic algorithm for optimization: magnetic charged system search", Acta Mech., 224(1), pp. 85-107 (2013).

10. Yang, X.S. "A new metaheuristic bat-inspired algorithm", in: Nature Inspired Cooperative Strategies for Optimization (NISCO 2010). Studies in Computational Intelligence, 284, pp. 65-74 (2010).

11. Rao, R.V., Savsani, V.J., and Balic, J. "Teachinglearning-based optimization algorithm for unconstrained and constrained real-parameter optimization problems", Eng. Optimiz., 44(12), pp. 1447-1462 (2012).

12. Kaveh, A. and Mahdavi, V.R. "Colliding bodies optimization: A novel meta-heuristic method", Comput. Struct., 139, pp. 18-27 (2014).

13. Sadollah, A., Eskandar, H., Bahreininejad, A., and Kim, J.H. "Water cycle, mine blast and improved mine blast algorithms for discrete sizing optimization of truss structures", Comput. Struct., 149, pp. 1-16 (2015). 
14. Gonçalves, M.S., Lopez, R.H., and Miguel, L.F.F. "Search group algorithm: A new metaheuristic method for the optimization of truss structures", Comput. Struct., 153, pp. 165-184 (2015).

15. Mirjalili, S.A. "The ant lion optimizer", Adv. Eng, Softw., 83, pp. 80-98 (2015).

16. Mirjalili, S.A. and Lewis, A. "The whale optimization algorithm", Adv. Eng. Softw., 95, pp. 51-67 (2016).

17. Kaveh, A. and Ilchi Ghazaan, M. "A new metaheuristic algorithm: vibrating particles system", Scientia Iranica, Trans Civil Eng, 24(2), pp. 551-566 (2017).

18. Kaveh, A., Applications of Metaheuristic Optimization Algorithms in Civil Engineering, Springer, Switzerland (2017).

19. Kaveh, A., Computational Structural Analysis and Finite Element Methods, Springer Verlag, Springer International Publishing, Switzerland (2014).

20. Kaveh, A. and Ilchi Ghazaan, M. "Enhanced colliding bodies optimization for design problems with continuous and discrete variables", Adv. Eng. Softw., 77, pp. 66-75 (2014).

21. Kaveh, A. and Malakouti Rad, S. "Hybrid genetic algorithm and particle swarm optimization for the force method-based simultaneous analysis and design", Iran. J. Sci. Technol., 34(B1), pp. 15-34 (2010).

22. Kaveh, A. and Bijari, Sh. "Simultaneous analysis, design and optimization of trusses via force method", Struct Eng Mech, Int J., 65(3), pp. 233-241 (2018).

23. Kaveh, A. and Hassani, M. "Simultaneous analysis, design and optimization of structures using force method and ant colony algorithms", Asian J. Civil Eng. (Building \& Housing), 10(4), pp. 381-396 (2009).

24. Kaveh, A. and Ahmadi, B. "Simultaneous analysis, design and optimization of structures using the force method and supervised charged system search algorithm", Scientia Iranica, Trans. A: Civil Eng., 20(1), pp. 65-76 (2013).

25. Kaveh, A. and Talatahari, S. "Optimum design of skeletal structures using imperialist competitive algorithm", Comput. Struct., 88, pp. 1220-1229 (2010).

\section{Biographies}

Ali Kaveh graduated from the Department of Civil Engineering at the University of Tabriz in 1969. He continued his studies on Structures at Imperial College of Science and Technology at London University and received his $\mathrm{MSc}$, DIC and $\mathrm{PhD}$ degrees in 1970 and 1974, respectively. He then joined the Iran University of Science and Technology. Professor Kaveh is the author of 650 papers published in international journals and 155 papers presented at national and international conferences. He has authored 23 books in Farsi and 15 books in English published by Wiley, RSP, American Mechanical Society, and Springer.

Shima Bijari received her PhD from Civil Engineering Department of Iran University of Science and Technology. She received the BSc degree in 2010, MSc in 2012, and $\mathrm{PhD}$ in 2018. Her main expertise and experience are in the field of structural engineering and optimal design of structures. She is interested in metaheuristic algorithms and their applications. 